\title{
Effect of a feedback control by early secondary xylem formation on the outcome of competition between leafy shoots in apple (Malus $x$ domestica Borkh.)
}

\author{
A. Jebari and J. Crabbé \\ Morphogenèse Végétale Appliquée, Faculté des Sciences Agronomiques, Gembloux, Belgique
}

\section{Introduction}

From bud break onwards, a developing shoot induces, within its bearing stem, a strand of secondary xylem, which progressively expands basipetally along the stem and spreads tangentially around it. The rate of this process and the differentiated wood characteristics, e.g., frequency and width of vessels, depend upon the rate of shoot elongation (Jebari and Crabbé, in preparation). The varying conducting capacity resulting from these early events affects the outcome of shoot competition and plays a part in the complex control of the apical dominance syndrome, in woody plants.

\section{Materials and Methods}

On $1 \mathrm{yr}$ old apple trees, $\mathrm{cv} . \mathrm{MM}$ 106, the unique axis was pruned at $\mathrm{ca} 60 \mathrm{~cm}$ high before bud burst and debudded except for the 2 uppermost buds (designated as buds/shoots 1 and 2, 1 being the most distal) and, when stated, bud 4 or 5 , located on orthostichies next to bud 1 or 2 , respectively.

All shoots present were periodically measured. The degree of dominance between the 2 upper shoots is evaluated by the ratio of their lengths $\left(L_{1} / L_{2}\right)$. Furthermore, anatomical investigation was carried out in order to evaluate initiation and expansion of cambial activity, new secondary xylem characteristics and their variations.

The experiment was limited to the spring growth flush, i.e., from bud break to late June.

\section{Results}

On a pruned woody axis, the outcome of competition between the 2 uppermost shoots is very uncertain. When a large population of plants is pruned as stated above, a continuum is generally observed between 2 extreme habits: strong dominance of shoot 1 on one side and forking due to subequal elongation of both shoots on the other.

In fact, in most plants, shoot 1 has, owing to its distal position, a precedency (acrotony) which makes it start growing first - or, at least, make up some initial retardation and overtake shoot 2 - and then amplify its advance during the remaining season. However, when shoot 1 is very delayed, a fork arises because shoot 2 is only able to maintain its small 
1.2 .4

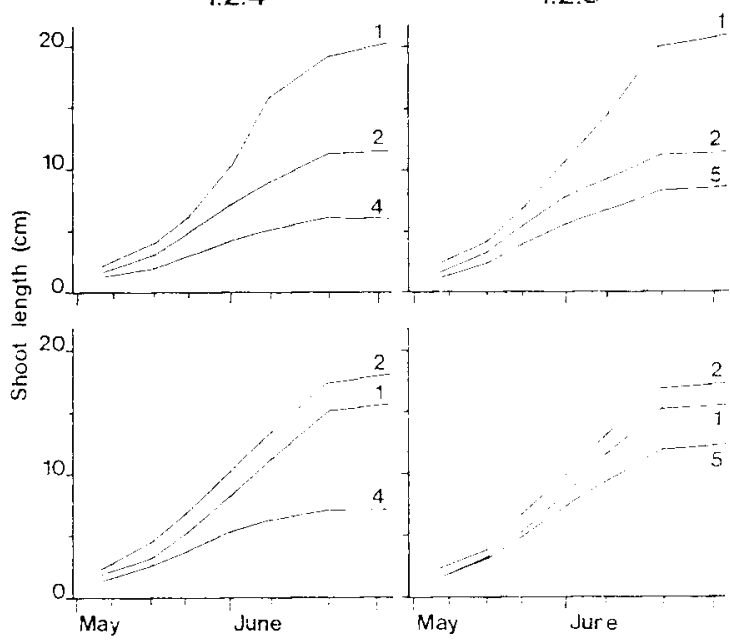

Fig. 1. Shoot elongation during spring growth period in 2 treatments and two subpopulations. Top: strong dominance of shool 1. Bottom: shoots 1 and 2 subequal. (1.2.4., 1.2.5: treatments refer to shoots left on pruned axis.)
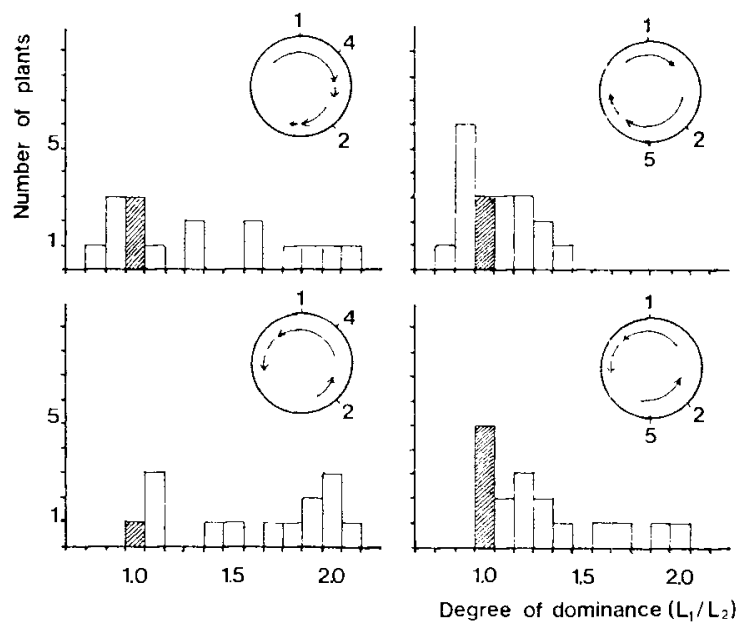

Fig. 2. Distribution of plants within treated population according to degree of dominance. Top: xylem strand of shoot 1 deviating towards shoot 2 insertion. Bottom: xylem strand of shoot 1 deviating away from insertion of shoot 2.

initial advance and cannot amplify it by growing faster than shoot 1 . The latter case is far from uncommon: it may amount to $40 \%$ of the total population, depending upon cultural conditions and treatments (see below). Fig. 1 shows these extremes in shoot elongation behavior in selected subpopulations. 


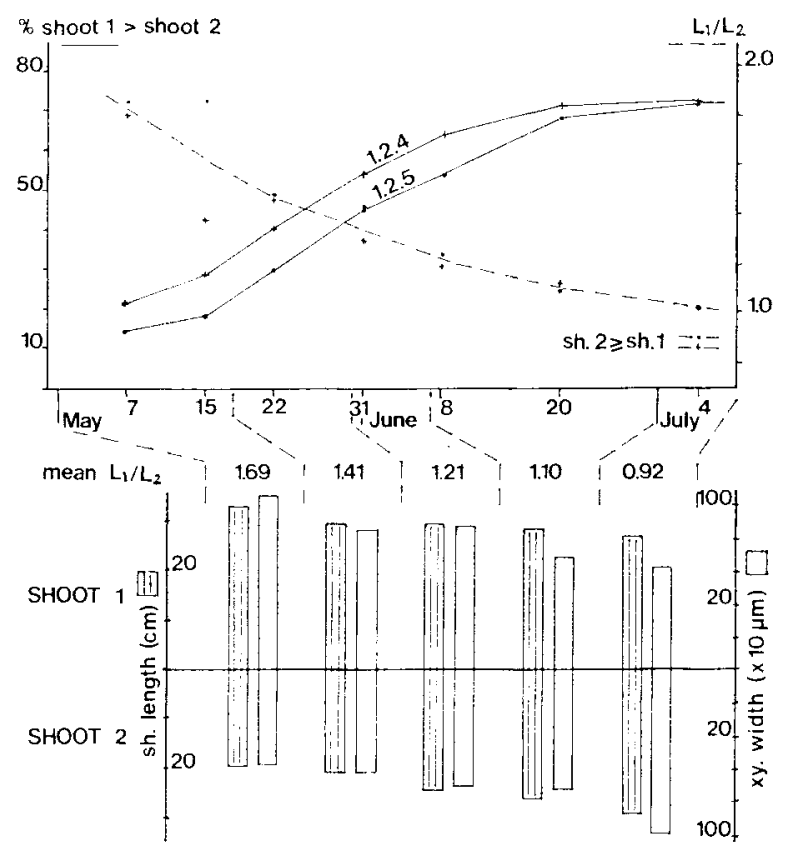

Fig. 3. Top: evolution of percentage of plants where shoot 1 overtakes shoot 2 during spring growth, compared to their final degree of dominance. Bottom: final shoot length and new xylem width of shoots 1 and 2 , in different groups according to time of takeover of shoot 1.

Among the conditions favoring either extreme behavior, we could mention the presence of a third shoot. For example, bud 4 which is next to bud 1's orthostichy increases the probability of strong dominance of this latter; whereas bud 5 near bud 2 favors the occurrence of a fork (Jebari and Crabbé, 1984; Crabbé, 1985).

This is, however, further complicated by the frequent helical deviation of the basipetal progression of the secondary xylem strands, which proceed seemingly at random clock- or counterclockwise. The outcome of competition between the 2 uppermost shoots consequently results altogether from which one sets growth on first, from the presence of a third bud and from the direction of this deviation. Fig. 2 displays the distribution of the degrees of dominance in selected subpopulations where deviation infringes upon the small angle between 1 and 2 (top) or on the larger one (bottom) and where bud 1 is favored by the presence of bud 4 (left) or bud 2 by that of bud 5 (right).

Anatomical investigation gives a possible interpretation of these rather surprising results. In a large population of plants differently treated, 5 groups were selected according to the time at which shoot 1 overtakes shoot 2 or to mean final degree of dominance. The last of these groups comprises the forked plants.

Considering the relative elongations of both shoots together with the relative width of new xylem formed below the shoots in the bearing axis, it clearly appears (Fig. 3) that, in the last group, 
shoot 2 invests relatively more matter in wood formation per unit shoot length than shoot 1 . The resulting increase in conducting capacity explains why shoot 2 successfully opposes and stays abreast of its competitor.

\section{Discussion and Conclusion}

The control of secondary xylem differentiation by shoot growth in the bearing stem below is not easy to explain. It differs markedly according to the complex dominance relations of the shoots: extreme habits, like strong dominance of the distal shoot or forking, proceed from different modes of regulation.

In the competition among shoots, the 'classical' hormone-directed nutrient diver- sion cannot be discarded as part of the explanation. However, cambial activity also interferes by long-term effects through variation in the conducting capacity of the main stem.

\section{References}

Crabbé J. (1985) Aspects of the apical control on branching in one-year-old caulinary axes of woody plants. Acta Univ. Agric. Brno 33, 555560

Crabbé J. (1986) Hiérarchie et opportunisme dans le développement de l'appareil caulinaire des arbres. Nat. Monspel. Ser. Bot. suppl. 339350

Jebari A. \& Crabbé J. (1984) Aspects of the interaction between the two upper shoots left on a pruned one-year-old axis in apple. 4th Congr. Eur. Fed. Soc. Plant Physiol., book of Abstr. 244-245 